\title{
Narrativas do espaço dos jovens do bairro Guajuviras/Canoas-RS
}

\section{Resumo:}

Nola Patrícia Gamalho ${ }^{1}$ Álvaro Luiz Heidrich ${ }^{2}$

O olhar para um bairro de periferia é um olhar que se transforma com os passos de quem percorre horizontalmente as ruas, senta nos bancos das praças, encontra pessoas, interlocutores, narradores de cotidianos estigmatizados. As periferias são produtos do processo de modernização e geração de riquezas nas metrópoles. Constituem-se como possibilidades concretas de sobrevivência na metrópole para os segmentos sociais mais pobres e que produzem, a partir de suas condições e localização nas cidades, representações que os inserem no processo de estratificação e hierarquização das cidades. Todavia, as periferias são também significadas, representadas a partir do cotidiano, da experiência, da trajetória de vida. Assim, percorremos através das narrativas dos jovens do bairro Guajuviras, periferia do município de Canoas (RS), representações produzidas no cruzamento e conflito entre a produção de sentidos que incidem e sentidos que são elaborados no plano do lugar, reconstruindo no diálogo as representações de juventudes e espaço.

Palavras-chave: Oralidade, representações, juventudes, espaço.

\section{Resumen:}

La mirada hacia un barrio de la periferia es una mirada que se transforma con los pasos de quien recorre horizontalmente las calles, se sienta en los bancos de las plazas, encuentra personas, interlocutores de vivencias cotidianas estigmatizadas. Las periferias son productos del proceso de modernización y generación de riquezas en las metrópolis. Se constituyen como posibilidades concretas de supervivencia en la metrópolis para los segmentos sociales más pobres y que producen, a partir de sus condiciones y ubicación en las ciudades, representaciones que los insertan en el proceso de estratificación y jerarquización de las ciudades. Sin embargo, las periferias son también significadas, representadas a partir de la vida diaria, de la experiencia, de la trayectoria de vida. Así, recorrimos, siguiendo el hilo de las narraciones de los jóvenes del barrio Guajuviras, periferia del municipio de Canoas (Rio Grande do Sul), representaciones producidas en el cruce y conflicto entre la producción de

\footnotetext{
${ }^{1}$ Doutoranda do Programa de Pós-Graduação em Geografia da Universidade Federal do Rio Grande do Sul. Email: nolagamalho@yahoo.com.br

${ }^{2}$ Professor Dr. Do Programa de Pós-Graduação em Geografia da Universidade Federal do Rio Grande do Sul. Email: alvaroheidrich@ufrgs.br
} 
sentidos que inciden y sentidos que se elaboran en el plano del lugar, reconstruyendo en el diálogo las representaciones de juventudes y espacio.

Palabras clave: Oralidad, representaciones, juventudes, espacio.

\section{Introdução}

As narrativas dos jovens do bairro Guajuviras revelam o imbricamento da ordem distante e próxima (LEFEBVRE, 2001), das táticas astuciosas e estruturas tecnocráticas (CERTEAU, 2009), no processo de construção de sentidos e representações de juventude e de espaço. As representações não são produtos acabados, sendo disputadas pelos diferentes atores sociais. No plano do lugar, do bairro, as representações hegemônicas são internalizadas de forma seletiva, sendo ressignificadas a partir da experiência, intenções e saberes desenvolvidos. Assim, juventudes e periferia são representações em constante movimento, sendo imprescindível identificar os mecanismos de sua produção e sua importância nas cidades contemporâneas, em particular os daquelas produzidas pelos jovens dessas periferias.

O bairro Guajuviras localiza-se na periferia social do município de Canoas, região metropolitana de Porto Alegre (RS). É um bairro recortado em unidades denominadas "vilas" e "setores". Essa distinção interna não é gratuita: refere-se a distintos processos de produção do espaço urbano, e as vilas e setores designam também distâncias sociais internas ao bairro. Um importante eixo de sentidos atribuídos ao espaço está na sua origem, marcada por ocupações e invasões, claramente em conflito com a importância atribuída à propriedade privada na sociedade capitalista. A distinção entre ocupações e invasões dá-se na fragmentação entre a primeira ocupação, que foi a do Conjunto Habitacional Ildo Meneghetti, programa de habitação popular da Cohab (Companhia de Habitação do Rio Grande do Sul), em 1987, e as invasões, que correspondem à autoconstrução de moradias e ruas nas áreas verdes adjacentes ao referido conjunto habitacional e que ocorreram no decorrer das décadas de 1990 e 2000, com destaque para o ano de 1999.

Paralelamente às representações vinculadas ao acesso ilegal do solo urbano, tem-se a violência urbana como fato e representação. A violência urbana reelabora sentidos e práticas da cidade, como a desconstituição dos espaços de apropriação, as práticas da rua, tão comuns às periferias urbanas. Assim, tem-se um intricado conjunto de elementos que atuam na produção das representações, mas como elas ocorrem no plano do lugar, das práticas dos jovens que têm nas ruas e no espaço do bairro elementos de pertencimento e de 
reconhecimento? Suas narrativas indicam alguns caminhos e desafios metodológicos para a construção de saberes a partir dos sujeitos e seus espaços vividos.

\section{O percurso na direção das narrativas}

Neste ponto do percurso, surge a questão de como deslocar o problema da materialidade do espaço para aspectos que envolvam subjetividades. O primeiro passo é o diálogo entre as disciplinas que têm desenvolvido metodologias qualitativas e problematizado sua pertinência e uso. O desafio de aventurar-se por geografias subterrâneas, por vozes silenciadas, impõe rigor e criatividade na execução e reflexão metodológicas. As narrativas do espaço imersas nas histórias de vida, nas práticas socioespaciais são o objetivo dessa aventura, porque pesquisar pressupõe desprender-se e perder-se no novo, no inusitado, buscando com isso recriar caminhos.

Perdemo-nos, então, pelas trilhas da periferia, pelo burburinho das vozes dos jovens do bairro Guajuviras, narradores do espaço que externalizam em suas falas os processos de estigmatização e a criatividade e subversão das práticas microbianas. As interpretações possíveis a partir dessas narrativas compõem esse espaço social com especificidades de lugar e com elementos estruturantes; pois produção e reprodução são indissociáveis. Operacionalmente, as metodologias qualitativas inserem, indissociavelmente, problemas e potencialidades. A inserção em campo, os diálogos com os narradores e as interpretações das narrativas e práticas exigem rigor e flexibilidade. As particularidades dessas etapas da pesquisa propiciam a produção de saberes que emergem do empírico exaustivamente analisado e articulado a concepções teóricas que potencializem a compreensão do fenômeno.

A oralidade é a principal ferramenta utilizada para identificar os sentidos atribuídos ao espaço pelos jovens do Guajuviras. As falas deram-se na combinação de técnicas de produção de dados: entrevistas não diretivas, conversas informais, grupos focais e registros em diário de campo. As múltiplas conversas compõem narrativas de vida e de espaço.

Sujeitos e espaços adjetivam-se mutuamente, como nos casos de "vila" e "vileiro", ou "favela" e "favelado". O espaço é central na vida desses sujeitos que o significam a partir da distância social (logo, de uma ordem distante) e de suas trajetórias. Esse imbricamento se dilui nas narrativas de vida, o que determina a dificuldade de identificá-lo. O dado, transformado em informação, está inserido em sistemas de significação dos atores sociais, devendo, portanto, ser compreendido a partir das teias de significados (GEERTZ, 1991), dos 
códigos e normas elaborados e internalizados pelos sujeitos. As narrativas comportam um mosaico de influências estruturais e locais, imbricando-as em narrativas de vida espaciais (LINDÓN, 2008).

Ao explorar suas memórias, o ator reinterpreta sua trajetória, em uma operação racional e emotiva. As narrativas não são lineares, coesas, mas, antes, uma espécie de colcha de retalhos de lembranças e de ações cotidianas que, ao serem reelaboradas, deixam de ser banais. O espaço vivido não é exatamente o espaço das histórias: as narrativas são versões e não se referem exclusivamente a fatos. Ao narrar suas histórias e práticas, o ator recria a realidade, representando-a. Essa diversidade de dados contidos nas narrativas exige estratégias que possibilitem sua interpretação. Ao atribuir aos sujeitos a posição de exploradores de suas memórias, tem-se como resultado elementos esperados e previstos nos referenciais teóricos e elementos novos, inusitados. Moraes (2003) associa essa diversidade a "uma tempestade de luz": múltiplas construções de sentidos que aparentam estar desconexos e desordenados, mas com os quais são produzidas novas ordens.

Os descaminhos e insurgências redirecionam o olhar do pesquisador, e o que se revela de forma difusa, demandando densas reflexões, é a emergência de conhecimentos novos. Assim, o problema surge de forma maleável, reelaborando-se no percurso, possibilitando com isso o desejo, o medo e a inovação. Ribeiro (1999) alerta para o "perigo da terra firme ao conhecimento", reconhecendo o medo frente ao inusitado, mas também a potencialidade de inovação ao adentrar em terrenos desconhecidos. É preciso abrir-se ao inesperado, reelaborando os pressupostos e direcionamentos no decorrer do percurso.

Parafraseando Tom Zé, talvez a melhor forma de percorrer a trajetória de pesquisa seja mesmo explicando para confundir, confundindo para esclarecer, iluminando para cegar e ficando cego para poder guiar ${ }^{3}$, porque a construção de saberes é potencializada quando é levantada em cima de desconstruções, estranhamentos, desconfortos. A aventura do caminho está em perder-se, descobrir outros planos, o inusitado, projetando a pesquisa para uma confusão que reflete e revela outras verdades, pois perder-se é parte inexorável do encontro com o outro e consigo mesmo.

A produção e interpretação de dados são qualitativas quando se abrem para o novo, para o que há de mais profundo nas narrativas. Prazer e medo são aspectos do mesmo processo, mas deve tratar-se de “(...) um pavor que desperte a vontade de inovar em vez de levar o estudante a procurar a terra firme, o terreno conhecido" (RIBEIRO, 1999, p. 190). A

\footnotetext{
${ }^{3}$ Música "Tô", do CD "Estudando o Samba".
} 
abertura de narrativas propiciadas pelas técnicas qualitativas pressupõe a disposição do pesquisador para acolher essa profusão de informações, aceitando também, caso se imponham, os descaminhos.

\section{Pesquisa de campo: os pesquisadores como estrangeiros e forasteiros do cotidiano}

O trabalho de campo opera com lógicas complementares, como as da proximidade e o estranhamento. A proximidade dá-se pela geração de mecanismos de aproximação dos atores sociais. Com ela, são mitigadas as distâncias inerentes aos distintos papéis sociais. O estranhamento é a permanência da atenção nos detalhes de um cotidiano em princípio banal e naturalizado, mas diferente aos olhos do observador. É indispensável a conjugação entre estranhamento e proximidade.

A partir da condição de forasteiro (SCHUTZ, 1999) ou de estrangeiro (SIMMEL, 1983), tem-se a inserção junto a um grupo de determinado território. Em nosso trabalho, consideramos o forasteiro como ocupando uma posição de aceitação e tolerância por parte do grupo social, e sua inserção propicia, no caso específico do pesquisador, o compartilhamento das experiências e histórias do grupo envolvido. $\mathrm{O}$ forasteiro marca uma posição geográfica: é alguém de fora, o que também suscita a curiosidade em relação a ele, posto o trabalho de campo ser uma relação permeada por trocas. O estrangeiro também remete a uma analogia geográfica, a do viajante, cuja posição é a de alguém que, embora não pertencendo ao grupo nem tendo partilhado suas experiências, estabelece um contato racional de proximidade e distância. Os pesquisadores podem situar-se dessa forma, porque eles também são moradores de cidades, homens, mulheres, torcedores...

O próximo/distante marca a dualidade da posição do pesquisador, que, para tecer compreensões a partir de dentro, precisa trilhar os percursos, entrar nas casas, conversar com os atores. O olhar transforma-se com as experiências dos lugares. Ao se percorrer ruas, praças, transformam-se as representações respectivas, e elas deixam de parecer lugares impenetráveis. A dualidade próximo/distante exige esforço e autorreflexão constantes por parte do pesquisador, que deverá, a cada momento, avaliar suas posturas e inserções em campo.

Ao realizar as filmagens para o documentário "Santiago" e, posteriormente, retornar ao material bruto, João Moreira Salles reflete sobre as barreiras impostas pelos papéis sociais 
que não foram ultrapassadas. Elas são expostas de maneira magistral, revelando não apenas o objeto, mas ele próprio. Assim, conta (e constata) Salles:

Essa é a última filmagem que fiz com Santiago. Ela me permite fazer uma observação: não existem planos fechados nesse filme, nenhum close de rosto. Ele está sempre distante. Penso que a distância não aconteceu por acaso: ao longo da edição entendi o que agora parece evidente. A maneira como conduzi as entrevistas me afastou dele. Desde o início havia uma ambiguidade insuperável entre nós, que explica o desconforto de Santiago. É que ele não era apenas o meu personagem e eu não era apenas um documentarista. Durante os cinco dias de filmagem eu nunca deixei de ser o filho do dono da casa e ele nunca deixou de ser o nosso mordomo (SALLES, 2005).

$\mathrm{Na}$ relação entre João e Santiago, preponderou a distância. Ainda que houvesse vínculos entre ambos, suas posições sociais prevaleceram, não apenas por parte de Santiago (o ator social), mas também de João (o documentarista). O pesquisador tem a responsabilidade de deixar os atores à vontade durante a atividade ou o acompanhamento das práticas espaciais. Sem deixar de ser quem ele é, deve desvencilhar-se de suas pré-concepções, preconceitos e perspectivas moralistas. A atenção e o questionamento da própria postura devem ser constantes, evitando com isso produzir compreensões estereotipadas ou estigmatizadas.

A inserção em campo junto a determinado grupo depende das relações pessoais desenvolvidas facilitadas por pessoas chave que possibilitem a entrada nos territórios pela conquista da confiança dos demais atores, pois o estrangeiro/forasteiro é visto como um estranho que busca saber de fatos da vida e do cotidiano, às vezes íntimos e outras, tidos como irrelevantes. Os diálogos com os jovens do bairro Guajuviras deram-se na articulação de grupos focais com jovens da rede pública de ensino, o que propiciou a continuidade de conversas com alguns jovens em outros momentos e a inserção junto a lideranças que auxiliaram na entrada nos diferentes espaços do bairro e no contato com as juventudes dessas divisões. Assim, tem-se uma diversidade de narrativas e de posicionamentos em relação às categorias aqui apresentadas: espaço e juventude.

A definição do espaço vivido a partir da experiência dos atores evidencia as relações multiescalares, uma vez que os sentidos da fé, do progresso, do lar, não são produzidos exclusivamente na ordem próxima. O espaço geográfico das experiências e sistemas de significado é antropocêntrico, logo, “(...) lleva consigo dificuldades metodológicas ampliadas porque solo puede estudiarse desde la perspectiva del sujeto que lo experimenta: no es posible verlo desde afuera del sujeto" (LINDON, 2008, p. 10). 
Ao narrarem suas histórias, os jovens as reconstituem reflexivamente, estabelecendo uma primeira interpretação. Selecionam fatos que são significativos, enquanto censuram outros. Percorrem ruas, falam sobre moradores e lugares, desejos, sonhos, frustrações. Suas narrativas partem das experiências e representações do lugar. O espaço é constituído simbolicamente em múltiplas escalas: as vilas, periferias, favelas já detêm significados anteriores às experiências dos atores, que acrescentam às múltiplas narrativas do lugar suas experiências em um misto de heranças e rupturas.

Representações e fatos não possuem existências separadas: enquanto as representações se constituem como interpretações que envolvem a subjetividade e a intersubjetividade, os fatos somente são compreendidos como representações, envoltos na construção de sentidos. Logo, os fatos são inseparáveis das representações, pois o ator só interpreta o real a partir de suas experiências, subjetividades e intersubjetividades. $\mathrm{O}$ espaço é produzido no acúmulo de múltiplas narrativas, de memórias herdadas (AMADO, 1995), mesclando as histórias sociais com as individuais. A memória herdada atua no presente e no futuro, constituindo esquemas inconscientes de ação e percepção, o habitus ao qual se refere Bourdieu (2009). Assim, as narrativas elaboram-se a partir das camadas de significados que o espaço vai adquirindo ao longo do tempo e são constantemente reformuladas.

As narrativas são espaços de criação pelos quais os atores recriam suas trajetórias e elaboram seus pertencimentos. Elas revelam não apenas as histórias de vida, mas sentidos e sistemas culturais pelos quais os atores se expressam. Um músico traz em suas composições os sentidos elaborados, um religioso expressa sua relação com o mundo a partir de pressupostos religiosos. Cada ator é um narrador específico, e cabe ao pesquisador refletir sobre os mecanismos para estimular as narrativas, compreendendo-as como leituras do mundo. O quadro de referências dos atores é aquele de suas narrativas, logo, o espaço e suas histórias devem ser lidos nos sistemas de sentido e/ou ideológicos que esses atores usam para expressar-se.

Não compreender uma narrativa é parte do processo, uma vez que a posição de forasteiro/estrangeiro se caracteriza por não dominar os códigos; todavia, é imprescindível sentir-se provocado e aventurar-se na descoberta de conhecimentos mais profundos. Há palavras, mas há também sentidos ocultos nas entrelinhas, nos silêncios e nas censuras. As narrativas dos jovens constituem essa aventura de diálogos, percursos, descobertas, provocações e encantamentos. 


\section{As narrativas do espaço: tecendo as representações das juventudes}

As representações emergem nas narrativas dos jovens, tecendo as definições de juventude e do bairro Guajuviras a partir de sua experiência (das práticas espaciais), de sua herança (as narrativas dos pais e vizinhos) e de elementos que ultrapassam a escala do lugar (como a mídia, representações da ordem distante). Constituem-se, assim, no atravessamento de múltiplas forças. Como aponta Ortiz (2005, p.65),

(...) o lugar pode ser definido como um espaço transglóssico, no qual se entrecruzam diferentes espacialidades. Para compreendê-lo, deveríamos nos debruçar sobre as situações concretas desse entrelaçamento.

A periferia é um espaço geográfico em que confluem representações do espaço e espaços de representação (LEVEBVRE, 2000). Deve ser compreendida como social e plenamente inserida nas dinâmicas da metrópole. Nela encontramos os símbolos da globalização, as relações travadas nas redes sociais, ao mesmo tempo em que são mantidas as relações de proximidade, de vida de bairro pautada nas práticas de apropriação, de um cotidiano encaixado ao lugar. Os espaços periféricos revelam sua indissociabilidade em relação à metrópole. Ao mesmo tempo em que são produtos dela, nela inserem seus sentidos, culturas, demandas... A periferia está na metrópole, assim como a metrópole está na periferia. Questionado sobre se o Guajuviras era bairro ou vila, um jovem deu uma resposta inusitada e desafiadora:

Eu diria assim: se Canoas é um Estado, o Guajuviras é a Capital. É muito vasto o conhecimento que se tem desse bairro, e a dimensão dele vista fora é muito grande. Se tu perguntar pra um morador se ele sabe que o Guajuviras ganhou um prêmio em Genebra, qual morador do Guajuviras sabe disso? ${ }^{4}$

As representações sobre espaços periféricos os extravasam, fazendo com que eles retornem como espaços hiper-reais (DI MÉO e BULÉON, 2009), como nas manifestações do hip-hop, funk e nas representações de espaços violentos. É recorrente a expressão: “dizem que o Guajuviras é...”. As periferias vistas da perspectiva externa não são exatamente as mesmas do olhar interno, ou seja, as representações do espaço não são exatamente as mesmas dos espaços de representação, ainda que exerçam mútua influência. Quanto maior a experiência do espaço, isto é, as práticas de apropriação que ultrapassam a propriedade da

\footnotetext{
${ }^{4}$ Entrevista com jovem de 24 anos, morador do Setor 2, em 28/08/2013.
} 
casa e se esparramam pelas ruas, praças, mercados, maior é a compreensão alicerçada no plano do lugar e, portanto, dos espaços de representação. Nesse imbricamento de representações, as ruas e praças são criminalizadas, o que acarreta a criminalização dos atores, como os jovens das periferias que têm nesses espaços importantes campos de formação, de aventura (BORJA, 2003) e aprendizado (CARRANO, 1999) e até mesmo de subversão.

A construção do ser jovem dá-se na transglossia de diversos feixes de forças, como os elementos do espaço e as diretrizes e quadros simbólicos de representações hegemônicas, seja no autorreconhecimento como jovem ou em sua negação. As representações reificadas que estruturam modos de ser, o enquadramento em faixas etárias, ou a juvenilização da sociedade, pautada em estéticas e modos de vida que rompem com a divisão etária, não coincidem com as formas como esses atores vivenciam a juventude. Jovens de 16 anos, jovens de 24 anos, cuja inserção no mundo do trabalho, a constituição de uma família própria, a atribuição de responsabilidades como as relativas ao cuidado dos irmãos mais novos, a contribuição para o complemento da renda familiar, resultam na relativização da condição de jovem, chegando, inclusive, a negá-la nalguns casos. Margulis e Urresti (1998, p. 5) salientam que

No todos los jóvenes son juveniles en el sentido de que no se asemejan a los modelos propiciados por los medios o por las diferentes industrias vinculadas con la producción y la comercialización de valores-signo que se relacionan con los significantes de distinción.

O contexto social é de jovens inseridos nas demandas de consumo, no mundo da mercadoria e, logo, de desejos. Também é um contexto de pobreza e de necessidade de contribuir com a renda familiar. O período de moratória é diferencial segundo o segmento social: "Esta 'moratoria' es un privilegio para ciertos jóvenes, aquellos que pertenecen a sectores sociales relativamente acomodados, que pueden dedicar un período de tiempo al estudio" (MARGULIS e URRESTI, 1998, p. 4). A distância entre os significados das representações que incidem sobre esses jovens e as experiências vividas conduz a uma relativização de sua condição juvenil, que, embora institucionalizada nas inserções em programas sociais, escola e trabalho, é negociada ou restringida à adolescência.

Tem muitos jovens que é quase um adulto, não é um jovem, entendeu? Só que, porque, como eu: eu não trabalho pra ficar com o dinheiro, eu trabalho pra ajudar minha mãe dentro de casa, porque só o meu pai trabalha. ${ }^{5}$.

\footnotetext{
${ }^{5}$ Grupo Focal: Escola Estadual Cônego José Leão Hartmann, alunos do segundo ano de ensino médio, em maio de 2012 .
} 
Jovem A: Quando tu é jovem, tu tem que começar a aprender a fazer escolhas sozinho, parar de ter sempre um adulto em cima de ti. Tem que parar e ver que a vida não é mais aquele desenho que tu sempre viu. Muitos jovens passam da fase de criança para a de adulto, eles não têm aquela fase da adolescência, aquela fase de jovem, entendeu?

Jovem B: Como eu, eu sou casada, eu tenho 17 anos, mas eu tenho a minha vida, a minha casa, eu tenho as minhas coisas. A gente tem uma vida mais de adulto, a gente é realmente, a gente sabe como é. ${ }^{6}$.

Embora sejam institucionalmente jovens, as experiências desses homens e mulheres, bem como suas práticas e tomadas de posição na estrutura familiar explicam que eles não se vejam como os jovens hegemonicamente definidos. As representações são maleáveis, sendo produzidas na conjunção contraditória de elementos: são jovens que internalizam a estética e a cultura juvenis imbricando-as com suas possibilidades de vivenciá-las. Assim, as representações transformam-se na experiência, que é distinta conforme o segmento social. A moratória é social e geograficamente distinta; para os jovens pobres, é o tempo de "marcar bobeira" (ABAD, 2002), e, para os jovens com maior capital cultural e econômico, é o tempo de prolongar a capacitação profissional.

Os jovens percebem-se em um "vir a ser" que os posiciona em um período de moratória, de preparação para ingressar na sociedade. "Ela pensa: 'mais além eu vou ser'. Mas não faz nada. Cada vez fica mais difícil da juventude atingir o seu lugar na sociedade (...)" "7. O argumento da jovem evidencia a internalização das noções da estratificação ao se localizar em um vazio do sistema de posições sociais, na espera do momento de se tornar alguém. O "não ser" (PONTES e PASINI, 2007) situa as juventudes em uma etapa intervalar (na que não são nem uma coisa, nem outra), em um "entre" sem especificidades.

O "não ser" é característico das juventudes pobres da periferia, que combinam formação educacional com a inserção no mercado de trabalho, ou cujo tempo vago lhes atribui a condição de risco. O projeto de "ser alguém" é construído nas múltiplas informações que dizem quem esses jovens devem ser, fragilizando com isso o que eles são, seu modo de vida, suas práticas, sua cultura. É uma violência simbólica que empobrece a diversidade ao deslegitimar as táticas astuciosas de sobrevivência, de visibilidade.

\footnotetext{
${ }^{6}$ Grupo Focal: Escola Estadual Cônego José Leão Hartmann. Alunos do primeiro ano de ensino médio, em abril de 2012.

${ }^{7}$ Grupo Focal: Escola Estadual Cônego José Leão Hartmann. Alunos do segundo ano de ensino médio, em maio de 2012 .
} 
Jovem A: Eu muitas vezes vi minha mãe passando dificuldades dentro de casa e não: eu vou trabalhar. E eu corri atrás. Se fosse pela minha mãe e meu pai eu só estudaria. Eles dizem: estuda pra daqui um tempo tu ser alguém na vida.

(...)

Jovem C: Eu sou um exemplo vivo. Quantas vezes eu escutei: "tu não vai conseguir". Porque eu quero coisas altas, eu quero ir além. Não por orgulho, mas porque eu decidi isso pra mim, entendeu? Eu vou aproveitar tudo que tem na minha volta. Quanta coisa que tem e eu posso aproveitar. Eu tenho que superar a minha capacidade. ${ }^{8}$.

Jovem: Eu acho que não sou mais jovem. Acho que eu não tenho mais os horários disponíveis dos jovens. Agora eu sou adulto, me sustento. Embora tenho o espírito de jovem. Eu sempre me virei, comecei a trabalhar com 16 anos. Sempre me virei, trabalhei no tribunal, em escritório, vendia produtos de beleza, fazia digitação na igreja. ${ }^{9}$.

Situar-se é um ato geográfico, pois colocar-se na sociedade é ultrapassar os limites da vida local, da vida de bairro. Crescer tem o sentido de vencer a cidade, colocando-se nela como alguém importante, útil, de um valor a ser descoberto. Trajetórias de abandono do estudo, trabalhos menos legitimados socialmente, vida circunscrita pelo lugar culminam por destituir esses jovens dos valores hegemonicamente aceitos.

A produção de representações é um campo em disputa no qual se pode incorrer em distorções e, por consequência, servir à dominação. A internalização das estruturas objetivas (BOURDIEU, 2007) orientam visões de mundo, ações e o processo de autorreconhecimento. Todavia, como assinalado anteriormente, é um campo em disputa, portanto as representações não são determinantes, mas ocorrem em conjugação com a criação e a recriação. A perspectiva de mundo que os jovens desenvolvem é articulada à sua condição socioespacial, sua localização e reconhecimento em uma estrutura hierarquizada com elementos da globalização, reproduzindo e produzindo representações. O hip-hop e o funk são exemplos de reelaboração desses quadros simbólicos, conferindo à periferia uma centralidade na produção de sentidos e histórias.

Se por um lado os jovens trabalhadores relativizam sua condição juvenil, por outro, os jovens que não trabalham e que têm seu tempo de ócio pautado em práticas espaciais são previamente criminalizados. A criminalização das práticas de permanência nas ruas e praças desconstrói o processo de apropriação da cidade. Todavia, nesse campo em disputa, a

\footnotetext{
${ }^{8}$ Grupo Focal: Escola Estadual Cônego José Leão Hartmann. Alunos do segundo ano de ensino médio, em maio de 2012

${ }^{9}$ Entrevista com jovem de 21 anos, morador da Vila Banhado, em 14/04/2013.
} 
internalização de estruturas objetivas e as múltiplas experiências produzem representações diversas.

Jovem: Bah, agora eu não sei mais o que é ser jovem, agora eu só trabalho, não faço mais nada.

Nola: agora tu não é mais jovem?

Jovem: Não. É que antes eu ficava vagabundeando, eu não trabalhava.

Eu ficava aí na praça, jogava uma bola, fumava um Beck. Agora não dá, agora tá ruim. ${ }^{10}$

Jovem A: Sempre tem uns que falam.

Jovem B: Sempre tem uns que acham.

Jovem A: Que o cara é maloqueiro por estar na rua.

Nola: E o que tem de legal de ficar na rua?

Jovem A: Ficar conversando. Que nem eu, quando não tem nada pra fazer eu venho aqui no Fulano, aí a gente fica conversando. Ou fica em casa só no computador mesmo. ${ }^{11}$

Nola: O que é ficar na rua que tu diz.

Jovem: Pra nós é uma coisa boa. Porque a gente acha amigo, a gente descobre coisas, mas ao mesmo tempo a gente tá correndo perigo. É muita, é muita... É legal, mas ao mesmo tempo é ruim. Porque a gente sabe as consequências da droga e os guris, e a gente... ${ }^{12}$

Juventudes e periferia têm mútua influência na elaboração de significados. Os jovens sofrem pela criminalização de seus corpos, estéticas e práticas socioespaciais ensejos de desconstrução do ser jovem. O tempo livre é criminalizado ao estar associado ao espaço público, ao tempo de estar nas esquinas, nas praças. Nesse sentido, as representações associadas ao modo de vida urbano minam espaços de convivência e de constituição de sujeitos. Contudo, esse processo não ocorre sem conflitos, pois a rua, praças e esquinas são referências de práticas e experiências comuns aos jovens. Os significados dos espaços são construídos e desconstruídos conforme as experiências do espaço desses jovens.

Jovem A: Só anda na rua quem não deve.

Jovem B: Só que não tem rixa.

Jovem A: Eu ando na rua.

Jovem C: Eu fico nas esquinas e não uso nada ${ }^{13}$.

\footnotetext{
${ }^{10}$ Entrevista com jovem de 18 anos, morador do Setor 1, em 30/08/2013.

${ }^{11}$ Entrevista com jovens moradores de Ocupação Verde no Setor 5; Jovem A - 16 anos; Jovem B 18 anos; em18/08/2013.

${ }^{12}$ Entrevista com jovem de 15 anos, moradora da Nova Nancy, em 08/07/2013.

${ }^{13}$ Grupo Focal: Escola Municipal de Ensino Fundamental Erna Wurth, alunos do EJA, em outubro de 2012.
} 
O processo de internalização opera a partir de representações por vezes distorcidas. Contudo, paralelamente à internalização das estruturas objetivas, dá-se a criação e reelaboração do ser jovem, mas, principalmente, do ser jovem da periferia, em função de suas trajetórias de vida e sua reafirmação socioespacial. $O$ processo de produção das representações passa a incorporar as relações afetivas e de pertencimento; são representações cujas assimetrias não servem à dominação, mas à reafirmação de estar no mundo e estar ligado a um lugar específico. A reprodução da ordem social dá-se por fissuras, construindo a partir das práticas microbianas sentidos que, sem estarem descolados ou antagonizarem com a ordem estabelecida, apontam para outras ordens, ou para o desconforto e não reconhecimento de representações que incidem, mas não instituem plenamente os significados, uma vez que há múltiplas formas de se ter a experiência do espaço.

Jane Jacobs (2009) argumenta que as ruas são perigosas se as pessoas as esvaziam, ou seja, o enfraquecimento de práticas espaciais e, no caso de bairros residenciais, o enfraquecimento das relações de vizinhança, culminam por tornar as ruas e praças espaços interditados. Eles não são previamente perigosos, mas contém potencialidades e artes de conviver (MAYOL, 2009). São espaços de formação, como frequentemente definidos pelos jovens.

É, eu tenho uma cabeça formada e conhecimento através da rua. Mas isso vem de uma questão que é viver na rua e não viver da rua. Na rua tu encontra de tudo. Se tu tiver uma mente aberta, tu consegue aprender com tudo, agora se tu tem uma mente que não é tão aberta, às vezes as coisas chegam em ti de outra forma ${ }^{14}$.

Jovem: Foi. Mas eu aprendi um monte de coisas, aprendi a andar na rua, aprendi a saber onde eu piso, onde eu não piso. Com quem eu lido, com quem eu não sei.

Nola: E como é andar na rua?

Jovem: Como eu posso te dizer... do jeito mais certo que tiver que andar. Porque hoje o mundo tá de ponta, tá de cabeça pro ar, e tudo o que tu faz é motivo de briga. Tu tem que te cuidar bem, te portar bem. Não pode falar muito, quem fala demais sempre acaba se estrepando. Sempre tem inimizade na volta. Tem o amigo, mas tem o inimigo falando: "ah, fulano falou isso de ti”. Na rua sempre tem que cuidar o que tu fala ${ }^{15}$.

Artes de convivência, espaços de aventura e aprendizado são práticas que consolidam o espaço como um campo de forças no qual se potencializa o próprio ativismo de bairro e o

\footnotetext{
${ }^{14}$ Entrevista com jovem de 24 anos, morador do Setor 1 , em 28/08/2013.

${ }^{15}$ Entrevista com morador de 20 anos do Recanto dos Seus, em 11/06/2013.
} 
pertencimento espacial. É por meio dessas práticas socioespaciais que os sujeitos se constituem, elaboram saberes e pertencimentos. Assim, o espaço passa pelo processo de desalienação, sendo significado mais pelas relações de proximidade do que pela ordem distante, preponderando o lugar na transglossia. As representações são partilhadas e, de certa forma, o individual contém e está contido no social.

Os jovens se constituem em relação com as práticas da rua, seja em sua efetivação ou negação. Todavia, as ruas são espaços de possibilidades, logo uma das realidades é a prática do uso da maconha ou o tráfico de drogas.

Nola: Tu pode me falar da experiência do jovem de estar na rua, de viver nas praças, de encontrar amigos, tu pode me falar um pouco de como é isso? Jovem: Não é tão bom.

Nola: Não é tão bom?

Jovem: Não é tão bom. Ah, o cara já pega o jeito, se eu pudesse ter trabalhado...

Nola: Como? Desculpa, eu não entendi.

Jovem: Não, é que não é tão bom, na verdade. Se eu tivesse trabalhando... Nola: Se tu tivesse trabalhando na época? Por que se tu tivesse trabalhando seria melhor?

Jovem: Porque eu ia me adiantar mais, né? Agora não deu ${ }^{16}$.

Jovem: A rua é ruim, qualquer rua é ruim. Mas se tu não tem cabeça, é pior ainda. Tipo, no Guajuviras, o que tu vai ver? Vai chegar na esquina e estão fumando maconha. Vai ter um que vai te oferecer maconha ${ }^{17}$.

Os becos, esquinas e ruas são caracterizados como potencialmente perigosos, e os sujeitos que se apropriam desses espaços são criminalizados. Todavia, no cotidiano, são lugares de encontro e permanência de jovens, tão característicos de bairros de periferias. A vida de bairro tem como qualidade a permanência de relações de vizinhança, de espaços de encontros e de reconhecimento. No entanto, os sentidos que incidem na significação dessas ruas e espaços os reelaboram como malditos. Nesse processo, as práticas espaciais pautadas por relações de proximidade esvaecem, o que propicia práticas regradas em espaços privados e encontros entre iguais.

A rua pode ser o espaço do espetáculo ou do temor. Nessa lógica, as esquinas são identificadas como áreas promotoras de infração, mas, para os jovens, são (também) lugares de encontro, de práticas; eles constituem os espaços como locais de aventura, ou educativos. Os mesmos símbolos adquirem sentidos, significados distintos, produzindo representações do espaço e espaços de representação. Assim:

\footnotetext{
${ }^{16}$ Entrevista com jovem de 18 anos, morador do Setor 1 , em 30/08/2013.

${ }^{17}$ Jovem de 18 anos, morador do Setor 1 , em 04/06/2013.
} 
Eu brincava aqui na rua, eu cresci com a gurizada.

Fiz badernas, saía por aí fazendo arruaça, mexendo com os guris de outras vilas, como a São José, a São Miguel. (...)

Eu faltava aula pra ir pro laguinho ali no Pôr-do-Sol. Eu conheço todo mundo aqui do Guajuviras, alguns eu só cumprimento, não tenho bolo com ninguém ${ }^{18}$.

A rua é um importante elemento da vida do bairro pelo que se consolidam as relações de convivência e conveniência. Ela marca a transição entre o privado e o público, entre a casa e a cidade. Entre permanências e rupturas do urbano, nos bairros da periferia, a rua persiste como espaço de práticas. Não é um lugar de predomínio de estranhamentos ou passagem, mas de permanência e visibilidade, onde os sujeitos são vistos e reconhecidos. "En la calle yo participo. Soy también espectáculo, para los demás. De buen o mal grado, figuro en el texto social (...)" (LEFEBVRE, 1978, p. 95).

\section{Conclusão}

A construção dos sentidos e práticas do espaço a partir do uso de oralidades implica um mergulho nas práticas microbianas, nos espaços horizontais, constituindo-se em um olhar de dentro. As narrativas permitem, a partir de uma densa análise, identificar o imbricamento da ordem próxima e distante, ou seja, das internalizações de representações do espaço e de sua recriação nos espaços de representação. As vilas e periferias possuem significados que extrapolam seus limites, podendo reafirmar a cultura do lugar, mas também constituir-se como espaços hiper-reais.

As representações são um campo em disputa, logo a fala de uma moradora veiculada em uma reportagem de uma emissora de $\mathrm{TV}^{19}$ identificando Guajuviras como a "Bagdá brasileira" encontra no bairro ressonância e negação, conforme as práticas do espaço. Em relação aos jovens, as narrativas apontam para importantes embates sociais, tais como os relativos à experiência da condição juvenil, que nem sempre é vivenciada ou é significada como tempo de marcar bobeira.

As narrativas dos jovens evidenciam que a relação entre as práticas socioespaciais transforma a rua em um complexo mosaico representacional, revelando as múltiplas

\footnotetext{
${ }^{18}$ Entrevista com jovem de 18 anos, morador do Setor 6, em 23-01-2013.

19 Programa Globo Repórter da emissora de TV Rede Globo, apresentado em 19 de abril de 2013. Disponível em: $<$ http://www.youtube.com/watch?v=a6427advGBo $>$, acesso em outubro de 2013.
} 
experiências do espaço na periferia. Todavia, a criminalização das práticas de permanência na rua e praças, alicerçadas nos discursos do tipo "[é preciso] tirar os jovens da rua", apenas enfraquece um sentido de cidade baseado na apropriação e nas relações de vizinhança. Esse processo conduz a menos cidade, menos diversidade. Se as ruas se tornam um campo de múltiplas possibilidades, cabe refletir e potencializar esse aspecto, fortalecendo as práticas do espaço (logo, os pertencimentos) e reelaborando representações e a inserção desses espaços na hierarquia socioespacial da metrópole em formas menos hierárquicas e mais horizontais.

\section{Referências}

AMADO, Janaína. O grande mentiroso: tradição, veracidade e imaginação em história oral. História, São Paulo, 14, p. 125-136, 1995.

BERGER, Peter; LUCKMANN, Thomas. A construção social da realidade: Tratado de sociologia do conhecimento. Petrópolis: Vozes, 1985.

BORJA, Jordi. La ciudad conquistada. Madrid: Alianza Editorial, 2003.

BOURDIEU, Pierre. O poder simbólico. 10 ed. Rio de Janeiro: Bertrand Brasil, 2007.

CARRANO, Paulo Cesar Rodrigues. Angra de tantos reis: práticas educativas e jovens tra(n)çados da cidade. Tese de doutorado - Programa de Pós-graduação em Educação, Universidade Federal Fluminense, 1999.

CERTEAU, Michel de. A invenção do Cotidiano 1: Artes de fazer. 16 ed. Petrópolis, RJ: Vozes, 2009.

DI MÉO, Guy.; BULÉON, Pascal. L'espace social. Lecture géographique des sociétés. Paris: Armand Colin, 2007.

GEERTZ, Clifford. A interpretação das culturas. Rio de Janeiro: LTC, 1991.

HIERNAUX, Daniel; LINDÓN, Alicia. La periferia: voz y sentido en los estudios urbanos. Papeles de Población: Nueva Época. Año 10, no 42, p. 101-123, 2004.

HIERNAUX, Daniel. Los imaginarios urbanos: de la teoría y los aterrizajes en los estudios urbanos. Revista Eure. Vol. XXXIII, nº 99, p. 17-30, 2007.

JOVCHELOVITCH, Sandra. Os contextos do saber: representações, comunidade e cultura. Petrópolis: Vozes, 2008.

KUNDERA, Milan. A insustentável leveza do ser. Rio de Janeiro: Nova Fronteira, 1985.

LEFEBVRE, Henri. De lo Rural a lo urbano. Barcelona: Peninsula, 1978. 
La production de l'espace. 4 ed. Paris: Anthropos, 2000.

. O direito à cidade. São Paulo: Centauro, 2001.

LINDÓN, Alicia. De las geografías constructivistas a las narrativas espaciales como metodologías geográficas cualitativas. Revista da Anpege, V. 4, p. 7-26, 2008.

Las narrativas de vida espaciales: una expresión del pensamiento geográfico humanista y constructivista.

MARTINS, José de Souza. A sociabilidade do homem simples: cotidiano e história na modernidade anômala. 2 ed. São Paulo: Contexto, 2008.

MAYOL, Pierre. O bairro. In: CERTEAU, Michel de.; GIARD, Luce; MAYOL, Pierre. A invenção do cotidiano 2: morar, cozinhar. 10 ed. Petrópolis (RJ): Vozes, 2011. p. 37-45.

MICHELAT, Guy. Sobre a utilização de entrevista não-diretiva em sociologia. In: THIOLLENT, Michel. Crítica metodológica, investigação social e enquete operária. São Paulo: Polis, 1980. p. 191-212.

MORAES, Roque. Uma tempestade de luz: a compreensão possibilitada pela análise textual discursiva. Ciência \& Educação, V. 9, nº 2, p. 191-211, 2003.

ORTIZ, Renato. Um outro território: ensaios sobre a mundialização. São Paulo: Editora Olho d'Água, 2005.

RIBEIRO, Renato Janine. Não há pior inimigo do conhecimento que a terra firme. Tempo Social, São Paulo, V.11, nº 1, p. 189-195, maio de 1999.

SALLES, João Moreira. Santiago. Rio de Janeiro: Vídeo filmes, 2007. DVD (107 min).

SCHUTZ, Alfred. El forastero. Ensayo de psicología social. Estudios sobre la teoría social. Buenos Aires: Amorrortu Editores, 1974. p. 95-107.

SIMMEL, George. O estrangeiro. In: SIMMEL, George. Sociologia. São Paulo: Ática, 1983.

THIOLLENT, Michel. Crítica metodológica, investigação social e enquete operária. São Paulo: Polis, 1980.

TOM ZÉ. Tô. Álbum Estudando o Samba, 1976. 